\title{
Análise da paisagem e do uso e cobertura das terras no nordeste brasileiro, litoral semiárido
}

\section{Analysis of the landscape and land use changes in the Brazilian northeast, semiarid coast}

\author{
Wellynne Carla de Sousa Barbosa ${ }^{1}$ \\ Gustavo Souza Valladares ${ }^{2}$
}

\author{
Palavras-chave: \\ Geotecnologias \\ Sistemas Geoambientes \\ Mapeamento
}

\begin{abstract}
Resumo
A presente pesquisa busca fazer o levantamento das mudanças acontecidas na evolução da cobertura do solo no município de Cajueiro da Praia, Piauí, no período de 2000 e 2015, utilizando-se de técnicas de Sensoriamento Remoto e Geoprocessamento. Foi feita a classificação supervisionada de imagens LANDSAT 8 e LANDSAT 5, instrumentos imageadores OLI/TIRS e TM respectivamente, anos de 2015 e 2000, através do método Maxver, processadas no software Arcgis 10.2, possibilitaram a produção dos mapas de uso e cobertura e a dinâmica da cobertura das terras. A análise identificou nove classes de uso e cobertura das terras, que demonstraram alterações observadas a partir da dinâmica entre as duas datas. A análise destes dados, juntamente com dados socioeconômicos dos censos e pesquisas realizadas pelo Instituto Brasileiro de Geografia e Estatística - IBGE mostrou um contexto de mudanças do uso e cobertura das terras, com um crescimento da área urbana, a diminuição da área de mangue e o aumento dos corpos hídricos do município. A mudança no quantitativo da população do município ocorre perceptivelmente em sua área litorânea, o aumento dos corpos hídricos se dá especialmente devido ao crescimento de tanques de carcinicultura. As questões da legislação ambiental são fatores que podem explicar a recuperação de algumas áreas de vegetação, assim como seu descumprimento explica a perda de outras, como a vegetação de mangue, o qual foi observado ao longo do trabalho.
\end{abstract}

\section{Keywords:}

Geotechnology

Geoenvironmental Systems Mapping

\begin{abstract}
The Brazilian northeast coast has tourism potential, and in the last decades its landscapes have been impacted by the expansion of tourism activity. The present research aimed to survey the change $s$ that occurred in the evolution of soil cover in the municipality of Cajueiro da Praia, Piauí, in 2000 and 2015, using Remote Sensing and Geoprocessing techniques. The supervised classification of images LANDSAT 8 and LANDSAT 5, OLI/TIRS and TM imager instruments, respectively, in 2015 and 2000, using the Maxver method, processed in the Arcgis 10.2 software, made possible the production of the maps of
\end{abstract}

\footnotetext{
${ }^{1}$ Universidade Federal do Rio de Janeiro - Instituto de Geociências - LAGESOLOS - Rio de Janeiro, RJ, Brasil. wellynnekarla@hotmail.com

${ }^{2}$ Universidade Federal do Piauí. Coordenação de Geografia. Bolsista Produtividade em Pesquisa CNPq - Nível 2. Teresina, PI, Brasil. valladares@ufpi.edu.br
} 
use and coverage and the dynamics of land cover. The analysis identified nine classes of land use and land cover, which showed changes observed from the dynamics between the two dates. The analysis of these data, together with socioeconomic data from the census and surveys carried out by the Brazilian Institute of Geography and Statistics, showed a context of land use and land cover changes, with growth of urban areas, the increase of water bodies of the municipality. The change in the quantitative population of the municipality occurs perceptibly in its coastal area, the increase of water bodies is especially due to the growth of shrimp tanks. The issues of environmental legislation are factors that may explain the recovery of some vegetation areas, as their non-compliance explains the loss of others, such as mangrove vegetation, which was observed throughout the work.

\section{INTRODUÇÃO}

A zona costeira é bastante dinâmica, sendo de grande importância para os setores econômico, ecológico e social, se apresentando frequentemente, como alvo de diversas políticas públicas e estudos acadêmicos, com vistas a encontrar a melhor forma de gerir essas áreas. Nesse sentido, torna necessário o desenvolvimento de pesquisas nessa região.

Por serem ambientes atrativos do ponto de vista de sua geodiversidade e biodiversidade, a ocupação de regiões costeiras ocorre de forma constante, desde o início da humanidade. A diversidade da paisagem natural, representada pelas praias, dunas, restingas e manguezais, explicam a demanda populacional crescente nessas áreas.

Nesse contexto, o estudo tem o objetivo de analisar as mudanças no uso e cobertura das terras ao longo do tempo, com auxílio da ferramenta SIG, para dessa forma, fornecer subsídios ao planejamento e gestão ambiental do município de Cajueiro da Praia - PI.

O município de Cajueiro da Praia está situado no litoral do Piauí, vem chamando a atenção de vários turistas interessados em suas praias tranquilas, além da receptividade da comunidade local em um ambiente bucólico, sendo ainda o primeiro município brasileiro a receber o título de Patrimônio Natural do PeixeBoi Marinho.

Devido as atividades antrópicas promoverem a desestabilização das paisagens naturais, tais efeitos devem ser acompanhados e monitorados periodicamente (VENTURIERI et al., 2005). A lei Federal $n^{\circ}$ 12.651/2012 - Código Florestal Brasileiro vigente (BRASIL, 2012a) que regula e/ou protege o uso de áreas de vegetação como os mangues, as restingas e áreas interligadas como salgados e apicuns, ainda pode deixar brechas para uma inapropriada ou desordenada utilização podendo acarretar danos ao meio ambiente. Pois apesar de considerar os manguezais e restingas como áreas de preservação permanente, consideram as demais como "uso ecologicamente sustentável" (BRASIL, 2012b; ALBUQUERQUE et al., 2015).

Ao confeccionar e analisar o mapa do uso e cobertura das terras é possível avaliar temporal e espacialmente as mudanças ocorridas em um determinado local e período. A interpretação de imagens de satélite propicia a identificação de elementos pelos padrões de cor, profundidade, tamanho, forma, textura, localização, associação e arranjo. (ROSA, 2003; JENSEN, 2009).

\section{ÁREA DE ESTUDO}

O estado do Piauí possui uma área litorânea ao norte com uma extensão de $66 \mathrm{~km}$ compreendendo aproximadamente $1.200 \mathrm{~km}^{2}$, integrando os municípios de Cajueiro da Praia, Ilha Grande, Luís Correia e Parnaíba que podem ser acessados por meio de Teresina, Fortaleza e São Luís pelas rodovias BR - 343 BR - 222 e BR - 402, respectivamente (BAPTISTA, 2010).

A área de estudo corresponde ao município de Cajueiro da Praia (mapa 1), tem aproximadamente 7.163 habitantes, segundo IBGE (2010). Foi fundado pelo desmembramento de $281,75 \mathrm{~km}^{2}$ do município de Luís Correia, em 1995, localizado no litoral piauiense, em uma Área de Preservação Ambiental. Está situado no extremo norte do Estado, a $402 \mathrm{~km}$ da sua capital, Teresina, tendo a praia de Barra Grande como um dos seus principais pontos turísticos. Limita-se ao norte com o Oceano Atlântico, ao sul e a oeste com o município de Luís Correia e a leste com Estado do Ceará (IBGE, 2010). 
Mapa 1 - Localização do município de Cajueiro da Praia- PI

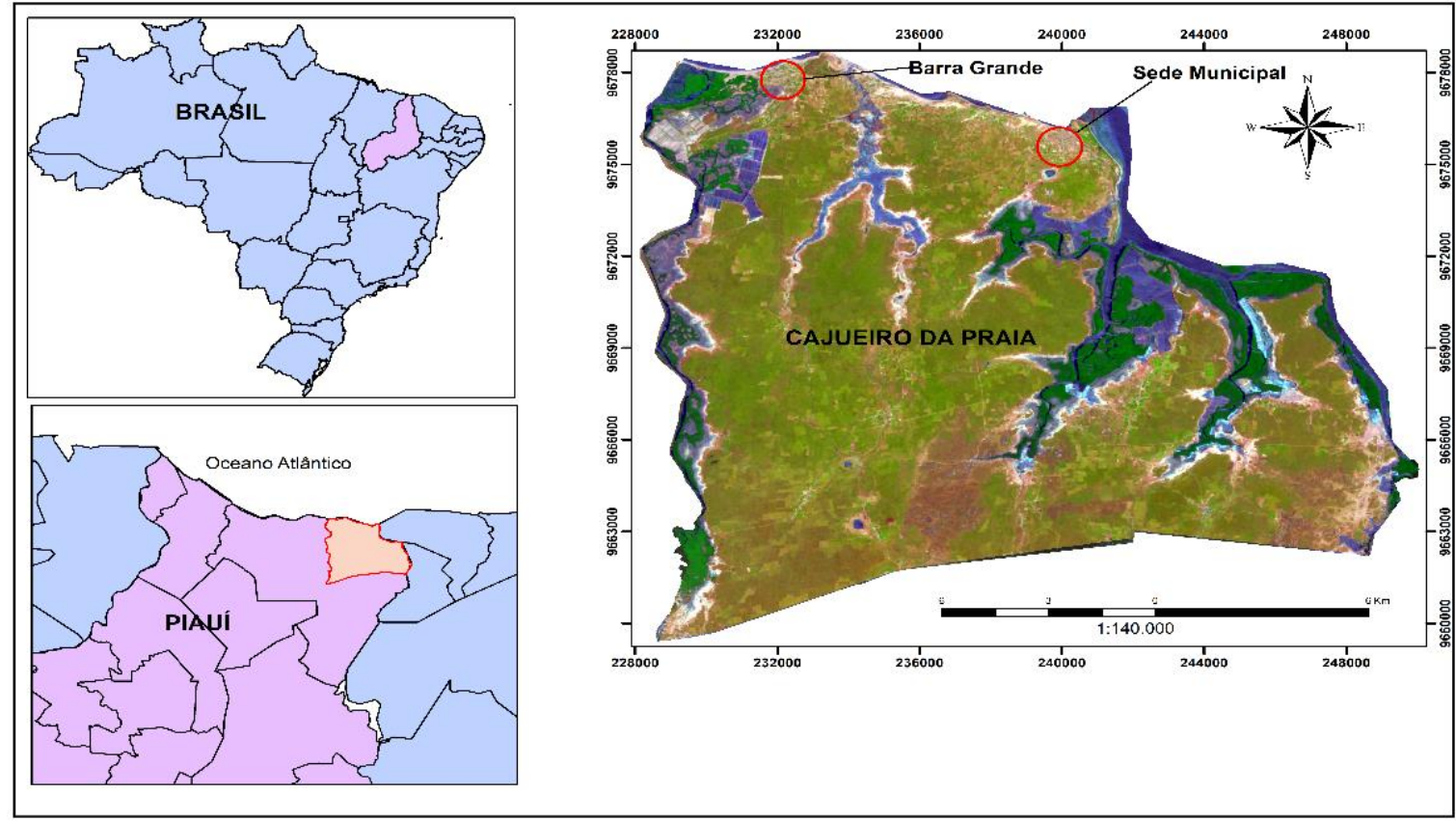

Fonte: Imagem Landsat 8. Org.: dos Autores, 2019

O município de Cajueiro da Praia por estar inserido na região litorânea do estado do Piauí caracteriza-se pela ocorrência de sedimentos terciários do Grupo Barreiras, e por sedimentos do período Quaternário, representados pelas dunas e aluviões. No Sul afloram rochas do précambriano esses dados tiveram por fundamento a base cartográfica da Companhia de Pesquisa de Recursos Minerais- CPRM (CPRM, 2006).

\section{MATERIAIS E MÉTODOS}

\section{Mapeamento e dinâmica do uso e cobertura das terras}

O estudo foi composto por duas etapas, a primeira relacionada à elaboração dos mapas de uso e cobertura da terra correspondente a dois períodos, uma do ano 2000, e outra 15 anos depois, em 2015. A segunda etapa concerne no cruzamento numérico e espacial dos mapas resultantes e a análise da dinâmica de uso e cobertura da terra, a partir da acurácia dos mapas.

A proposta do mapa de uso e cobertura do município, foi executado utilizando como base imagens orbitais, a classificação dessas imagens foi realizada de modo supervisionado, através do método automatizado de máxima verossimilhança, que consiste num método geral para estimativa de parâmetros, especialmente em casos de distribuição normal (JENSEN, 2009), utilizou-se também a interpretação visual na identificação das classes.

No intuito de alcançar os objetivos da pesquisa foram utilizadas imagens LANDSAT 8 e LANDSAT 5, instrumentos imageadores OLI/TIRS e TM respectivamente, a escolha está relacionada a facilidade e gratuidade em obter as imagens, além de uma relativa boa resolução, a escolha da cena obedeceu ainda alguns critérios, tais como, a menor percentagem de cobertura de nuvens, período de estiagem e a melhor visualização do município.

Dessa forma para analisar a evolução multitemporal do uso das terras no município de Cajueiro da Praia-PI, foi selecionada uma imagem orbital da série LANDSAT 5 sensor TM (órbita/ponto 219/62) de 15 de outubro do ano 2000 e outra imagem da série LANDSAT 8 sensores OLI/TIRS (órbita/ponto 219/62) com data em 09 de outubro de 2015. Foi utilizado também no auxílio a construção dos mapas, imagens orbitais RapidEye de 2014 dos meses de julho e agosto e 2012 dos meses de julho e setembro obtidos junto ao Ministério do Meio Ambiente (MMA).

As imagens de satélite utilizadas têm resolução espacial de 30 metros no caso da série LANDSAT, e 5 metros no caso da RapidEye, a área de estudo foi percorrida para a acurácia, verificação dos diferentes usos e coberturas das terras comparando com as identificadas no mapa. Para a análise da dinâmica de uso e cobertura das terras foram sobrepostos os mapas das duas diferentes datas, no intuito de interpretar a dinâmica, nesse recorte temporal. 
No software Arcgis 10.2 foi utilizada a ferramenta que permite fazer a classificação supervisionada da imagem para a construção do mapa de uso e cobertura, essa classificação é baseada no uso de algoritmos para se determinar os pixels que representam valores de reflexão próprios para uma determinada classe (CÂMARA et al., 1996).

\section{Acurácia do mapa de uso e cobertura das terras}

No sentido de minorar o erro associado aos dados estatísticos, utilizou-se o índice kappa ( () , que é uma variável que pode ser quantificada após a construção da matriz de erros, sendo um dado que afere o grau de concordância dos elementos, gerando, assim, um aspecto de confiabilidade e precisão dos dados classificados segundo a Equação 1: (PERROCA; GAIDZINSKI, 2003).

$$
\kappa=\frac{N \sum_{i=1}^{r} x_{i i}-\sum_{i=1}^{r}\left(x_{i+} x_{+1}\right)}{N^{2}-\sum_{i=1}^{r}\left(x_{i}+x+x_{i}\right)}
$$

$\mathrm{Na}$ Equação1, $\kappa$ indica o índice de concordância, $N$ corresponde ao número de observações (pontos amostrais); $r$ é o número de linhas da matriz de erro; $x_{i i}$ são as observações na linha $i$ e coluna $i ; x_{i+}$ é o total marginal da linha $i ; x_{+1}$ indica o total marginal da coluna $i$.

Para a análise de $\kappa$, é importante saber que ele varia no intervalo de 0 a 1 isto é, quanto mais próximo de 1, melhor será a qualidade dos dados classificados. Vários são os índices para agrupar esses dados quantitativos para qualitativos, entre eles, pode ser destacado o de Fonseca (2000), conforme apresentado na Tabela 1.

Tabela 1 - Relação índice-desempenho $\kappa$.

\begin{tabular}{c|c}
\hline Índice $\kappa$ & Desempenho \\
\hline$<0$ & Péssimo \\
$0<\kappa \leq 0.2$ & Ruim \\
$0.2<\kappa \leq 0.4$ & Razoável \\
$0.4<\kappa \leq 0.6$ & Bom \\
$0.6<\kappa \leq 0.8$ & Muito Bom \\
$0.8<\kappa \leq 1.0$ & Excelente \\
\hline
\end{tabular}

Fonte: Fonseca (2000).

É importante esclarecer que na confecção dos mapas foram consideradas nove classes, entretanto para a matriz de confusão, a classe correspondente à área urbana não foi considerada, em função de sua pequena expansão areal, sendo esta, mapeada em fase posterior de forma manual, portanto, foram utilizadas oito classes para a análise da matriz de confusão.

\section{RESULTADOS E DISCUSSÃO}

A classificação feita no município de Cajueiro da Praia permitiu a definição de nove classes de uso e cobertura das terras: área urbana, corpos d'água continentais, cordão arenoso/banco de areia, área úmida, solo exposto, vegetação I (mangue), vegetação II (restinga), vegetação III (caatinga), vegetação IV (carrasco) (ver Quadro 1).

$\mathrm{Na}$ análise e produção do mapa não foram identificadas lavouras tendo em vista a resolução de 30 metros das imagens LANDSAT e a dimensão das áreas cultivadas, este tipo de uso encontra-se associado à vegetação caatinga, carrasco e solo exposto.

A classe de solo considerou o solo exposto presente nas estradas, assim como, regiões próximas a corpos hídricos e área urbana. Já a classe da área úmida atua em vários pontos do mapa, sobretudo pela existência de bastante água no município. 
Quadro 1 - Relação entre classes e descrição utilizada no mapa de uso e cobertura.

\begin{tabular}{|c|c|}
\hline $\begin{array}{l}\text { CLASSES DE USO E } \\
\text { COBERTURA DA TERRA }\end{array}$ & DESCRIÇÃO \\
\hline Área urbana & $\begin{array}{l}\text { Espaços modificados pelo homem para diversos usos, } \\
\text { especialmente construção civil. }\end{array}$ \\
\hline Corpos d'água & $\begin{array}{l}\text { Compreende os principais cursos d'agua da região, tais } \\
\text { como o rio Arraia, Camurupim, Carmelo, Carpina, } \\
\text { Ubatuba, além de lagos e lagoas diversos. }\end{array}$ \\
\hline $\begin{array}{l}\text { Cordão arenoso/bancos de } \\
\text { areia }\end{array}$ & $\begin{array}{l}\text { Compreende uma faixa de areia alongada próximo a } \\
\text { linha de praia. Nesse caso, corresponde ainda a bancos } \\
\text { de areia localizados em regiões de áreas úmidas }\end{array}$ \\
\hline Área úmida & $\begin{array}{l}\text { Compreende a áreas que durante o tempo de cheia } \\
\text { ficam inundadas, algumas utilizadas na } \\
\text { carcinicultura. }\end{array}$ \\
\hline Solo exposto & $\begin{array}{l}\text { É correspondente às áreas onde toda a cobertura } \\
\text { vegetal do solo foi removida, principalmente pelo uso } \\
\text { antrópico. }\end{array}$ \\
\hline Vegetação I (mangue) & $\begin{array}{l}\text { Vegetação de transição entre os ambientes terrestres e } \\
\text { marinhos, composta por espécies que são típicas para } \\
\text { estes locais. }\end{array}$ \\
\hline Vegetação II (restinga) & $\begin{array}{l}\text { Vegetação comum em áreas litorâneas, localizado } \\
\text { especialmente em terreno arenoso e salino, próximo ao } \\
\text { mar, pode variar entre herbácea, arbustiva e arbórea }\end{array}$ \\
\hline Vegetação III (caatinga) & $\begin{array}{l}\text { Formação vegetal típica de regiões com baixo índice de } \\
\text { chuvas, forte presença de arbustos com galhos } \\
\text { retorcidos e com raízes profundas }\end{array}$ \\
\hline Vegetação IV (carrasco) & $\begin{array}{l}\text { Formação vegetal que abrange caatingas arbustivas de } \\
\text { solos pedregosos, capoeiras (vegetação secundária) e } \\
\text { áreas de vegetação aberta com arbustos de pequeno } \\
\text { porte }\end{array}$ \\
\hline
\end{tabular}

Org.: dos Autores, 2019.

O reconhecimento destas classes proporcionou a identificação da dinâmica da cobertura do solo, no período proposto, 2000 e 2015, favorecendo a segregação da vegetação e dos outros tipos de cobertura da terra. A classificação multitemporal da cobertura do solo se confirmou como uma importante ferramenta de monitoramento ambiental, permitindo a espacialização das classes identificadas nos diferentes anos, como apresentado nos mapas (Mapas 2 e 3). 
Mapa 2 - Uso e cobertura das terras de Cajueiro da Praia, Piauí (ano 2000).

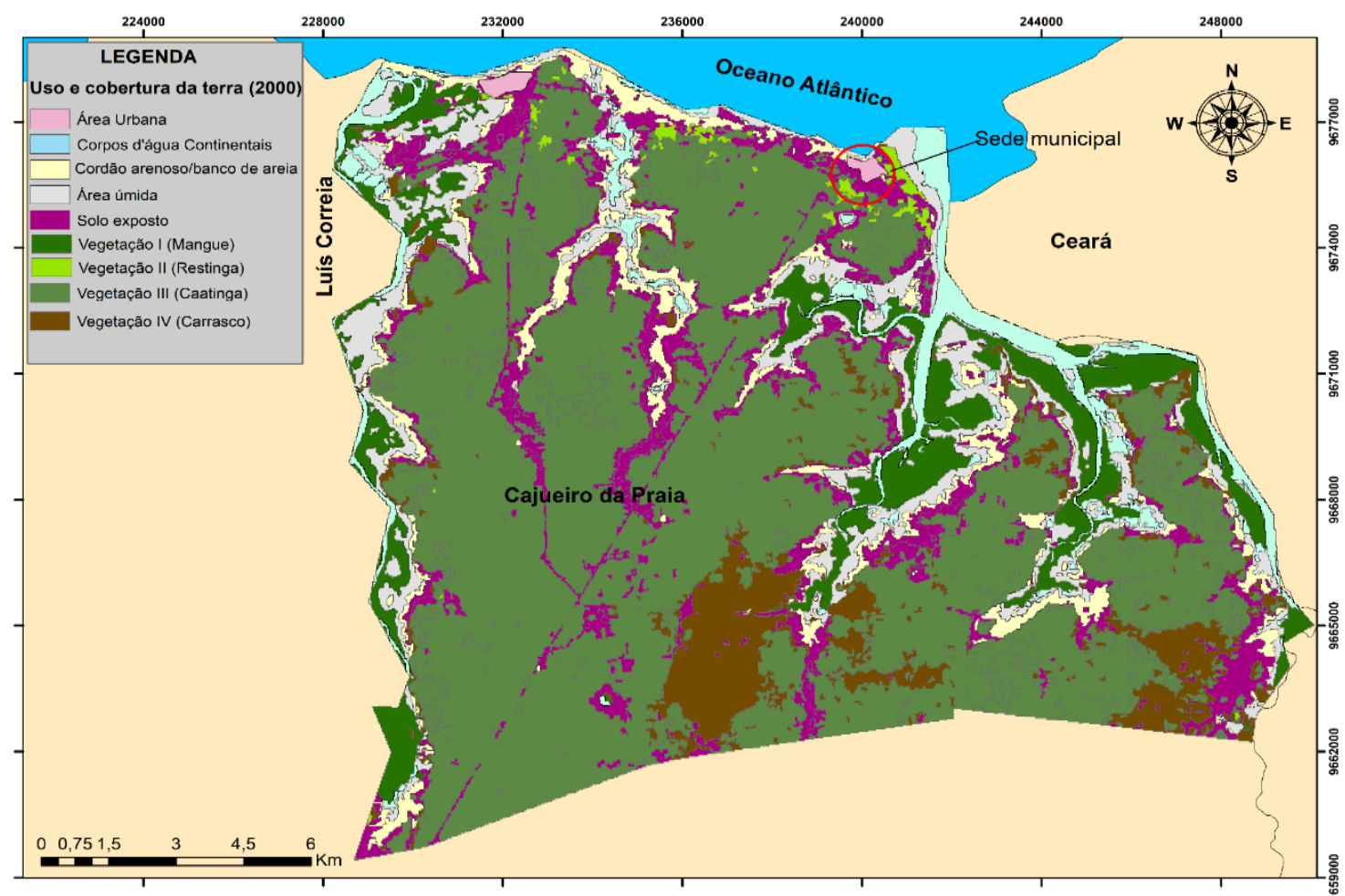

Org.: dos Autores, 2019.

Mapa 3 - Uso e cobertura das terras de Cajueiro da Praia, Piauí (ano 2015)

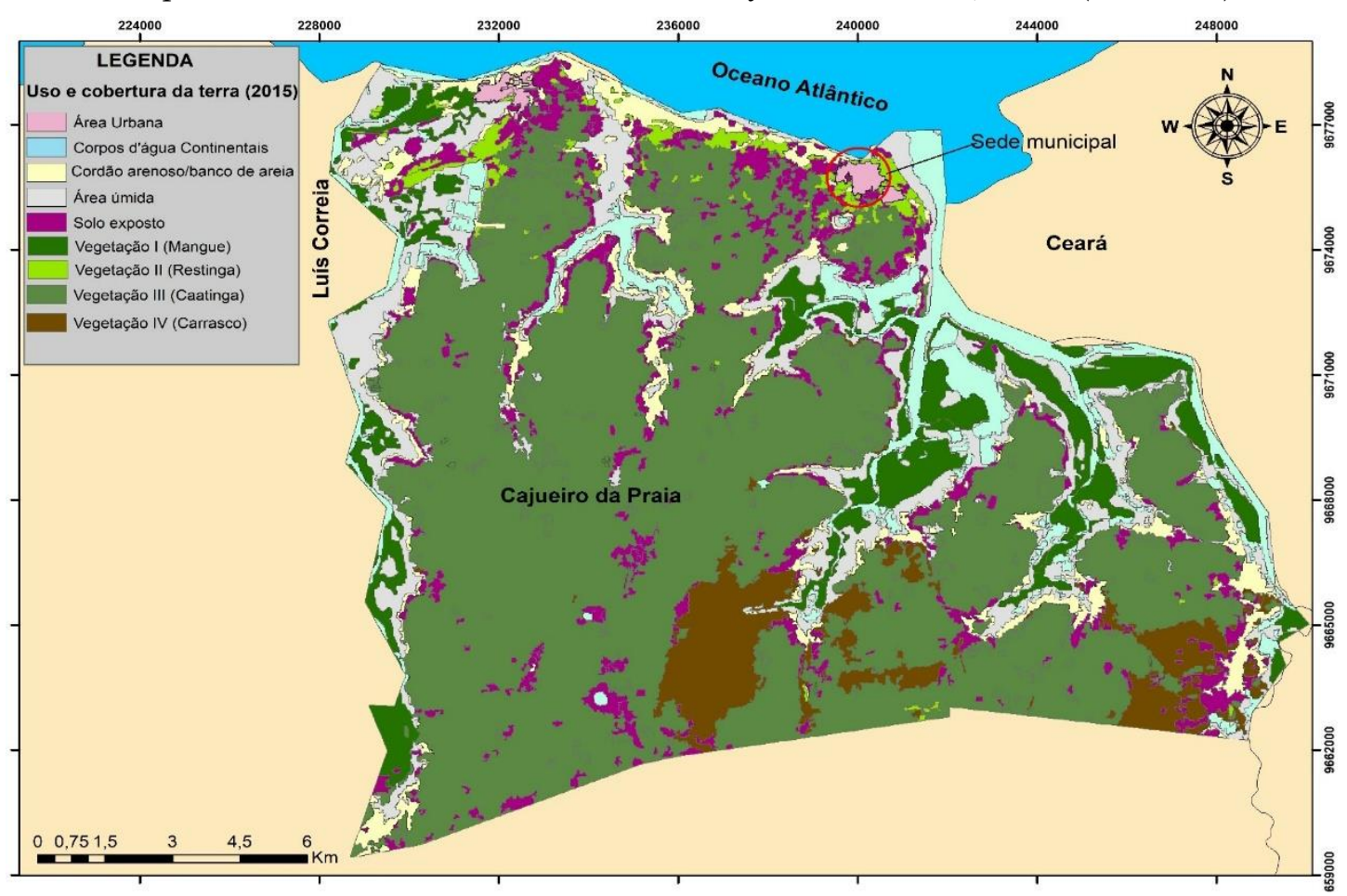

Org.: dos Autores, 2019.

A Tabela 2 mostra ainda as áreas das classes de 2000 e 2015 em km² utilizadas na elaboração da dinâmica do uso e cobertura, além de suas respectivas simbologias. 
Tabela 2 - Classes dos mapas de uso e cobertura da terra.

\begin{tabular}{|c|c|c|c|}
\hline Classes & Simbologia & $\begin{array}{l}2000 \\
\mathbf{k m}^{2}\end{array}$ & $\begin{array}{l}2015 \\
\mathbf{k m}^{2}\end{array}$ \\
\hline Área urbana & & 0,736027 & 1,362982 \\
\hline Corpos d'água & & 12,4133 & 16,72976 \\
\hline $\begin{array}{l}\text { Cordão arenoso/bandos de } \\
\text { areias } \\
\text { Área úmida }\end{array}$ & & $\begin{array}{l}15,07397 \\
21,78071\end{array}$ & $\begin{array}{l}14,71903 \\
29,41596\end{array}$ \\
\hline Solo exposto & & 30,27502 & 20,76829 \\
\hline Vegetação I (mangue) & & 21,77709 & 19,86575 \\
\hline Vegetação II (restinga) & & 1,707221 & 4,124797 \\
\hline Vegetação III (caatinga) & & 148,2258 & 150,0326 \\
\hline Vegetação IV (carrasco) & & 20,21495 & 15,18491 \\
\hline Total $\cong$ & & 272,20 & \\
\hline
\end{tabular}

Org.: dos Autores, 2019.

Acurácia do mapa de uso e cobertura das terras

A matriz de confusão faz uma correlação entre linhas e colunas, onde as colunas representam a verdade de campo enquanto as linhas participam como classes previstas. Observa-se que tanto na classificação do ano 2000 quanto no ano de 2015 obtiveram um índice $\kappa$ satisfatório, qualitativamente classificado como "excelente", de acordo com a Tabela 1, , entretanto, com uma diferença entre os valores, sendo que na data mais recente (2015) foi possível atingir maior nível de acerto.

Essas oito classes definidas previamente demonstraram um bom desempenho ao considerar a metodologia adotada, sendo o método Maxver eficiente para a classificação supervisionada pois permite uma separação com alto desempenho, como observado na matriz de confusão de cada imagem (Tab. 3 e 4).

Tabela 3 - Matriz de confusão de classificação (imagem LANDSAT 2000).

\begin{tabular}{|c|c|c|c|c|c|c|c|c|c|}
\hline \multicolumn{10}{|c|}{ Índice $K($ ano 2000$)=0,82$} \\
\hline CLASSES & $\begin{array}{l}\text { Veg. } \\
\text { mangue }\end{array}$ & $\begin{array}{c}\text { C. } \\
\text { água }\end{array}$ & $\begin{array}{c}\text { C. } \\
\text { arenoso }\end{array}$ & $\begin{array}{c}\text { A. } \\
\text { úmida }\end{array}$ & $\begin{array}{c}\text { S. } \\
\text { exposto }\end{array}$ & $\begin{array}{l}\text { Veg. } \\
\text { rest. }\end{array}$ & $\begin{array}{l}\text { Veg. } \\
\text { caat. }\end{array}$ & $\begin{array}{l}\text { Veg. } \\
\text { car. }\end{array}$ & $\begin{array}{l}\text { Total } \\
\text { Geral }\end{array}$ \\
\hline $\begin{array}{c}\text { Veg. } \\
\text { mangue }\end{array}$ & 6 & & & & & & & & 6 \\
\hline Água & & 3 & & & & & & & 3 \\
\hline C. arenoso & & & 4 & & & & & & 4 \\
\hline A. úmida & & & & 3 & & 1 & & & 4 \\
\hline S. exposto & 1 & & & & 6 & & 1 & & 8 \\
\hline Veg. rest. & & & & & & 3 & & & 3 \\
\hline Veg. caat. & & & & & 1 & & 7 & & 8 \\
\hline Veg. car. & & 1 & & 1 & & & & 1 & 3 \\
\hline Total Geral & 7 & 4 & 4 & 4 & 7 & 4 & 8 & 1 & 39 \\
\hline
\end{tabular}

Org.: dos Autores, 2019. Abreviaturas: Veg. mangue: vegetação de mangue; C. água: corpos d'água; C. arenoso: cordão arenoso; A. úmida: área úmida; S. exposto: solo exposto; Veg. caat: vegetação caatinga; Veg. car.: vegetação carrasco. 
Tabela 4 - Matriz de confusão de classificação (imagem LANDSAT 2015).

\begin{tabular}{|c|c|c|c|c|c|c|c|c|c|}
\hline \multicolumn{10}{|c|}{ Índice $K($ ano 2015$)=0,91$} \\
\hline CLASSES & $\begin{array}{c}\mathrm{C} . \\
\text { água }\end{array}$ & $\begin{array}{l}\text { Veg. } \\
\text { mangue }\end{array}$ & $\begin{array}{c}\text { C. } \\
\text { arenoso }\end{array}$ & $\begin{array}{c}\text { A. } \\
\text { úmida }\end{array}$ & $\begin{array}{c}\text { S. } \\
\text { exposto }\end{array}$ & $\begin{array}{l}\text { Veg. } \\
\text { rest. }\end{array}$ & $\begin{array}{l}\text { Veg. } \\
\text { caat. }\end{array}$ & $\begin{array}{l}\text { Veg. } \\
\text { car. }\end{array}$ & $\begin{array}{l}\text { Total } \\
\text { Geral }\end{array}$ \\
\hline C. água & 8 & & & & & & & & 8 \\
\hline Veg. mangue & & 7 & & & & & & & 7 \\
\hline C. arenoso & & & 4 & & & & & & 4 \\
\hline A. úmida & 1 & & & 4 & & & & & 5 \\
\hline S. exposto & & & & & 3 & & & & 3 \\
\hline V. restinga & & & & & & 5 & & & 5 \\
\hline Veg. caat. & & & & & & & 3 & 1 & 4 \\
\hline $\begin{array}{c}\text { Veg. } \\
\text { carrasco }\end{array}$ & & & & & & & 1 & 2 & 3 \\
\hline Total Geral & 9 & 7 & 4 & 4 & 3 & 5 & 4 & 3 & 39 \\
\hline
\end{tabular}

Org.: dos Autores, 2019. Abreviaturas: Veg. mangue: vegetação de mangue; C. água: corpos d'água;

C. arenoso: cordão arenoso; A. úmida: área úmida; S. exposto: solo exposto; Veg. caat.: Vegetação caatinga; Veg. car.: vegetação carrasco.

Logo, a elaboração da própria matriz em si, já é suficiente para o estabelecimento da acurácia das classes levantadas pois apresenta a porcentagem de assiduidade dos vários elementos relacionados a determinada classe, possibilitando ainda o entendimento e quantificação dos mal classificados, auxiliando dessa forma, no entendimento entre verdade de campo e a verdade observada no mapa.

\section{Análise do mapa de uso e cobertura das terras do ano 2000}

A partir da matriz do ano 2000 e do mapa de uso e cobertura foi possível observar que a vegetação de mangue, os corpos d'água, cordão arenoso e a vegetação de restinga, foram as classes que obtiveram o número máximo de acertos, revelando uma coerência entre o campo e a classificação da imagem de satélite, ou seja, todos os pontos classificados no campo obtiveram uma igual classificação no mapa.

Já dentre os pontos que obtiveram confusão, destaca-se a vegetação de carrasco, que é uma região diferenciada da vegetação que a cerca, sobretudo pela geologia e geomorfologia dessa área, a confusão se deu com a água e área úmida, provavelmente pelo tipo de reflexão que ocorreu entre essas classes na produção da imagem.

Ao analisar o mapa de uso e cobertura da terra do ano 2000, observa-se que a vegetação dominante caatinga ocupa a maior área do município, em campo, foi possível observar que ela varia entre regiões mais densas onde apresenta uma vegetação arbórea mais fechada e áreas mais abertas predominando vegetações mais arbustivas, variando entre essas duas composições em todo o município.

A vegetação Carrasco ganha destaque em meio a grande caatinga, esse termo vem sendo usado para designar diferentes tipos de vegetação do nordeste do Brasil e fora dele, abrangendo caatingas arbustivas de solos pedregosos, capoeiras (vegetação secundária) e áreas de vegetação aberta com arbustos de pequeno porte (ANDRADE-LIMA, 1978). Ainda não foram encontrados estudos consolidados sobre que tipo de espécie é o carrasco, se é uma vegetação ecotonal entre a caatinga e o cerrado, algum tipo resultante da degradação do cerradão, ou uma vegetação fóssil, representante de condições ambientais passadas.

Outro ponto relevante nesse mapa é o solo exposto, ele ganha destaque além das regiões próximas a áreas urbanas, também na extensão da rodovia, que fica evidenciado no mapa do ano 2000 por uma linha diagonal que corta o município de sul ao norte em direção à área litorânea, essa classe também é observada nas proximidades dos corpos hídricos, provavelmente devido a lavagem e erosão que ocorre nos períodos de alagamento e posterior seca.

Análise do mapa de uso e cobertura das terras do ano 2015

A análise identificou um crescimento na área urbana que em comparação a extensão do 
município ainda é pequena, mas que precisa ser monitorada para que esse crescimento não aconteça de forma desordenada.

A vegetação de mangue também ganha destaque no mapa, ela ocorre na região banhada pelos rios do município, de acordo com o IBGE correspondem aos rios Camurupim, Carpina, Carmelo, Ubatuba e Arraia. É uma área que merece atenção, pois é propícia a implantação de carcinicultura, devido sobretudo ao ambiente alagável. A dinâmica do uso e cobertura mostrou uma queda na área total dessa classe, provavelmente em decorrência dessa técnica de criação de camarões, no mapa os criadouros se apresentam próximos a essa vegetação, são identificados na imagem pela forma geométrica (geralmente retangular) divergente do padrão normal do entorno dos rios.

Para o ano de 2015 a matriz de erro demonstrou que área úmida, vegetação de restinga e carrasco obtiveram uma pequena confusão na classificação se comparado a classes identificadas no estudo de campo. Todas as outras classes tiveram $100 \%$ de acertos, isso se deve especialmente a melhor qualidade na imagem gerada pelo satélite LANDSAT 8.
No mapa de uso e cobertura da terra do mencionado ano observou-se que o solo exposto ficou espacialmente mais disperso, tendo uma maior concentração na região litorânea, provavelmente em decorrência da aglutinação de população nativa e turística, o mapa de 2015 não formou também uma linha diagonal cortando o município característico de rodovias e sim pontos mais aleatórios de solo exposto por toda área.

Visivelmente alguns pontos ocupados anteriormente por vegetação de mangue, deram espaço a corpos hídricos, especialmente em decorrência da construção de tanques de carcinicultura, como já mencionado anteriormente, e tipos de estresses que aumentam com a distância da linha d'água, além de consequências associadas à inundação pelas marés (acúmulo de sais, granulometria, intensidade das ondas) resultando em condições que podem prejudicar o desenvolvimento dessa vegetação. No ano de 2015 choveu proporcionalmente apenas $52 \%$ do que choveu em 2000 (Figura 1), na estação meteorológica mais próxima, que é Parnaíba, Piauí. Portanto o volume precipitado não é o fator responsável pelo aumento dos corpos hídricos de 2000 a 2015.

Figura 1 - Precipitação pluviométrica nos anos de 2000 e 2015 da estação meteorológica Parnaíba.

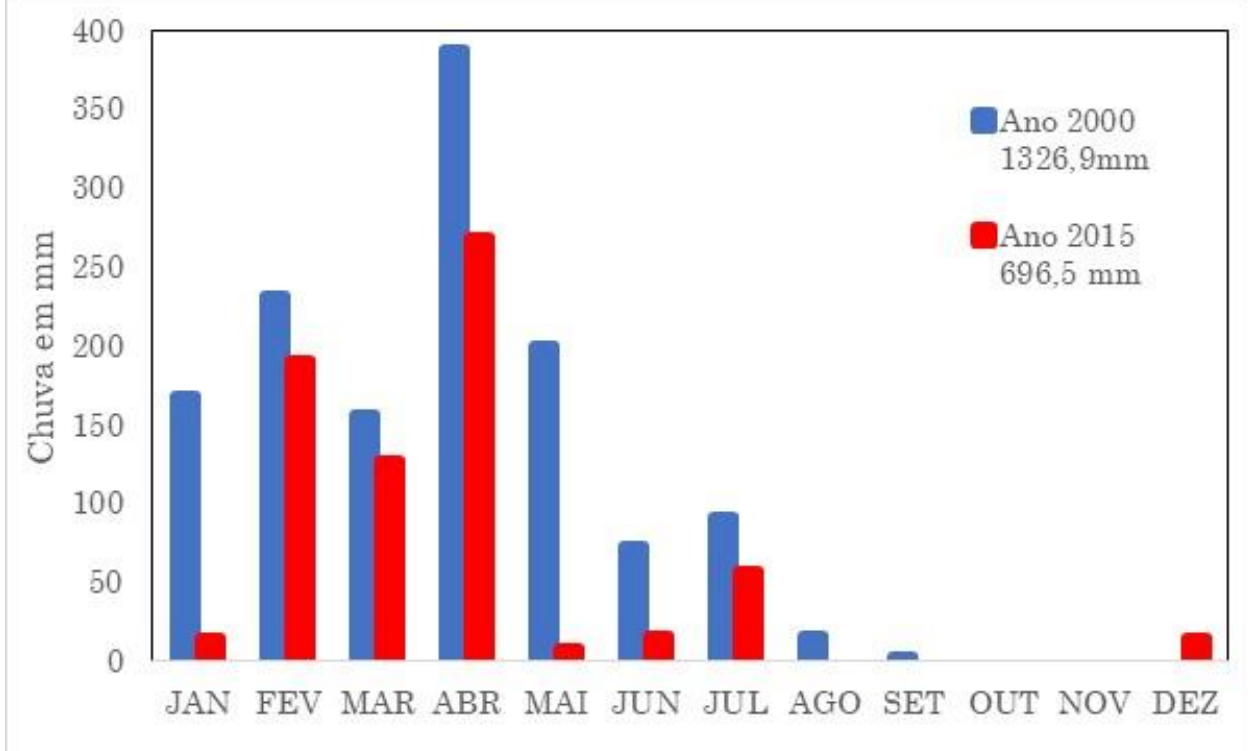

Fonte: INMET (2020). Org.: dos Autores, 2020.

A área urbana é outro ponto importante a ser observado, foi identificado um aumento na sua área total, isso se reafirma comparando a quantidade populacional do ano 2000 que segundo o IBGE era de 6.122 habitantes e em 2015 , 7.510, um aumento pequeno comparado a extensão do território, mas que cresce a cada ano especialmente na região próxima a linha da costa, demonstrando a importância do seu monitoramento.

Após o estudo de cada ano, foi feita a análise da dinâmica de cobertura do solo no qual foi possível perceber o processo de alteração na cobertura da terra ao longo do tempo, evidenciando os diferentes usos do solo no espaço geográfico. 
Dinâmica de uso e cobertura da terra nos anos de 2000 e 2015

Considerando essa dinâmica, observou-se que de 2000 para 2015 houve uma recuperação de áreas da vegetação caatinga $(54,45 \%$ para $55,12 \%)$ e redução da área de mangue (8,0\% para 7,30\%).

Outro ponto que chamou atenção foi $o$ aumento dos corpos d'água ao longo dos anos, alguns elementos que se apresentavam como outros aspectos no ano 2000, em 2015 aparecem como água, como é o caso do cordão arenoso $(11,43 \%)$, área úmida $(25,17 \%)$, solo exposto $(3,42)$, vegetação de mangue $(6,20 \%)$, como já mencionado anteriormente, isso se deve especialmente ao aumento de tanques utilizados na técnica de criação de camarões em viveiros, como mostra a Figura 2.

Figura 2 - Imagens de satélite da relação temporal entre áreas de corpos d'água em Cajueiro da Praia.

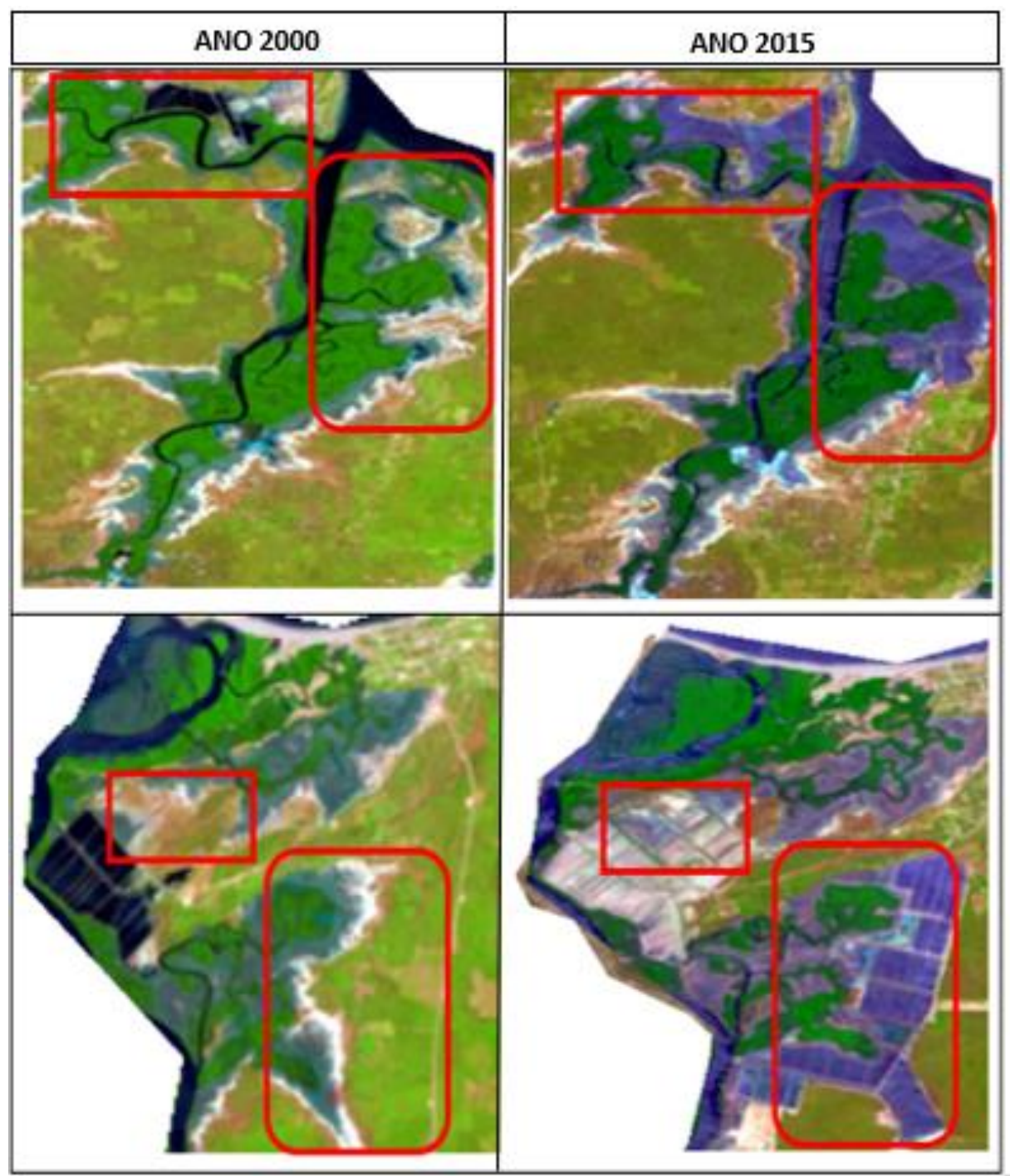

Fonte: Imagens LANDSAT (2000 e 2015). Org.: dos Autores, 2019.

Conforme mencionado Código Florestal, Lei Federal n ${ }^{\circ}$ 12.651/2012 (BRASIL, 2012a) a vegetação de mangue ou manguezal é posta como uma Área de Proteção Permanente enquanto a região de salgados e apicuns não o são. Essas áreas passíveis de uso como apicum e salgado são as mais procuradas por empreendimentos da carcinicultura. A Figura 2 mostra a evolução desse tipo de negócio no município, pois sustentam características como topografia de superfície plana, iminência de fonte de abastecimento, água marinha em quantidade e qualidade além do baixo valor econômico de compra da terra devido às condições de grande salinidade e propícia à inundações (ALBUQUERQUE et al., 2015).

Para facilitar a análise da dinâmica entre os anos, utilizou-se na Tabela 5 uma legenda com os seguintes elementos, conforme o Quadro 2. 
Quadro 2 - Descrição das classes e legenda da tabela da dinâmica de uso e cobertura da terra.

\begin{tabular}{|c|c|}
\hline CLASSES & DESCRIÇÃO \\
\hline Expansão de área urbana & $\begin{array}{c}\text { Corresponde às classes que sofreram } \\
\text { modificações ao longo dos anos transformando- } \\
\text { se em área urbana no ano de 2015 }\end{array}$ \\
\hline Preservação da vegetação & $\begin{array}{c}\text { Indica o quanto cada vegetação se manteve } \\
\text { preservada ao longos dos anos }\end{array}$ \\
\hline Expansão de corpos d'água & $\begin{array}{c}\text { Trata do aumento da quantidade de corpos } \\
\text { hídricos a partir da relação com outras classes }\end{array}$ \\
\hline Manutenção do solo exposto & $\begin{array}{c}\text { Identifica quanto se manteve de solo exposto } \\
\text { em comparação aos dois anos estudados }\end{array}$ \\
\hline Preservação da área úmida & $\begin{array}{c}\text { Percentual de área que se manteve úmida ao } \\
\text { longo dos anos }\end{array}$ \\
\hline Expansão do cordão arenoso & $\begin{array}{c}\text { Identifica as classes que sofrem alterações e } \\
\text { que em 2015 aparecem com aspectos arenosos }\end{array}$ \\
\hline
\end{tabular}

Org.: dos Autores, 2020.

É importante esclarecer que foram incluídos na legenda apenas os dados que obtiveram percentual maior que um, foi feita no sentido de facilitar a análise de alguns dos principais pontos identificados na tabela.

Como observado na tabela da dinâmica (ver Tabela 5), a área urbana também teve aumento pois cerca de $44,29 \%$ de solo exposto em 2000 , em 2015 se apresenta como área urbana, abrangendo ainda uma parcela do cordão arenoso, caatinga e vegetação de restinga, além de outros pontos, de uma forma menos expressiva.

Tabela 5 - Dinâmica de uso e cobertura da terra em Cajueiro da Praia, em \%.

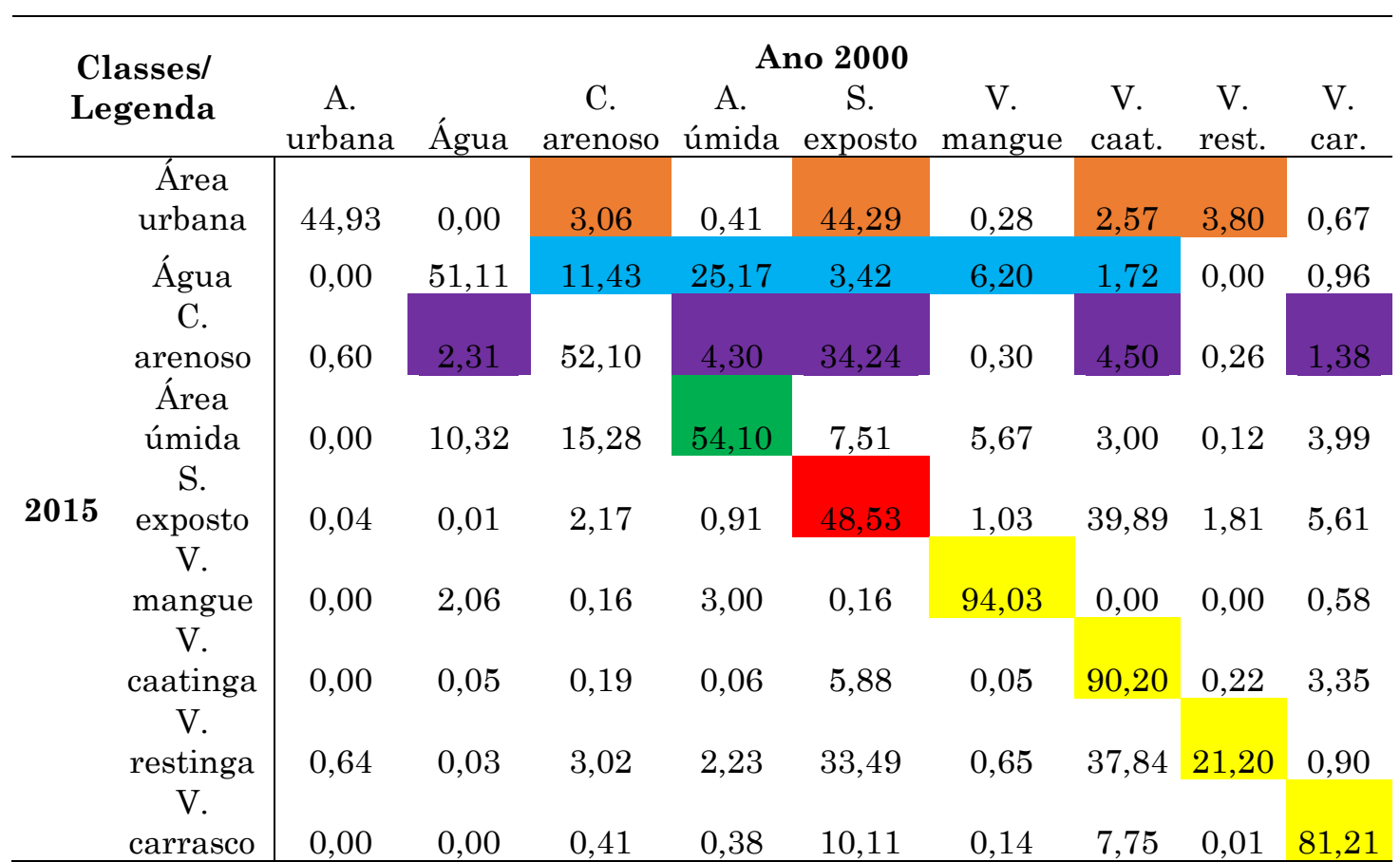

Fonte: Dados gerados a partir do software Arcgis 10.3. Org.: dos Autores, 2020. Abreviaturas: A. urbana: área urbana; C. arenoso: cordão arenoso; A. úmida: área úmida, S. exposto: solo exposto; V. mangue: Vegetação de mangue; V. caat.: Vegetação caatinga; V. rest.: Vegetação restinga; V. car.: Vegetação carrasco. = Expansão de área urbana; = = Preservação da vegetação; = Expansão de corpos d'água; = Manutenção do solo exposto; = = Preservação da área úmida; = Expansão do cordão arenoso.

$\mathrm{Na}$ área urbana do município, essa expansão identificada na dinâmica de uso e cobertura, deve-se, além do aumento populacional, ao crescimento do número de hospedagens, bares e restaurantes entre outros serviços ligados ao turismo, crescente sobretudo na região litorânea do município.

O cordão arenoso também obteve uma 
expressiva mudança ao longo dos anos, a análise mostrou que $34,24 \%$ do solo exposto em 2000 , se apresentou como cordão arenoso na data mais recente, alguns fatores podem ter influenciado essa mudança, tais como, a intensidade da ação erosiva, as atividades humanas como obras da construção civil em dunas ou até mesmo alterações climáticas.

A área úmida desenvolve um papel social e econômico insubstituível, por conter inundações que permitem a recarga de aquíferos, além de reter nutrientes, purificar a água e estabilizar zonas costeiras (MMA, 2007). No ano 2000 essa área correspondia a aproximadamente 21,780 $\mathrm{km}^{2}$, em 2015 ela se apresenta com $29,415 \mathrm{~km}^{2}$ esse crescimento se deve também às influências da carcinicultura.

A vegetação de mangue que correspondia a 8,00\% do total da área do município, teve uma redução para $7,30 \%$, apesar de parecer pouca perda, é uma área que apresenta ameaça constante devido ao já mencionado aumento dos tanques de carcinicultura, isso demonstra que a diminuição é progressiva e que pode continuar acontecendo ao longo dos anos com possibilidade real de prejudicar significativamente essa vegetação.

Quanto ao solo exposto da região observa-se no mapa que ele aparece mais concentrado nas regiões próximas a área urbana e a corpos hídricos, entretanto, pontos aleatórios em todo o território são observados, um ponto que pode ser associado a diminuição da sua área total ao longo desses anos de aproximadamente 30,275 $\mathrm{km}^{2}$ para $20,768 \mathrm{~km}^{2}$ é a modificação no tamanho da área de vegetação caatinga, como observado na tabela 5. Em algumas situações o solo exposto pode estar relacionado a solos cultivados que estão sem vegetação devido ao período das imagens ser de estiagens.

A vegetação caatinga tem o maior percentual total do município, 55,12\% do total do território de Cajueiro da Praia está situado dentro dessa classe, entre os biomas brasileiros, a caatinga é o menos conhecido botanicamente, as famílias mais numerosas em termos de espécies endêmicas são leguminosas (80) e cactácea (41). Dessas, várias estão em perigo de extinção (MMA, 2002). Esse bioma é um dos menos protegidos pelas unidades de conservação e proteção integral.

Outra vegetação identificada no estudo é a Restinga, ela varia entre herbácea, arbustiva e arbórea comum em áreas litorâneas, esta vegetação apresentou apenas $21,20 \%$ de preservação entre as duas datas, apesar de corresponder a 1,52\% da área total do território, teve um significativo crescimento desde o ano
2000 quando sua área correspondia a apenas $0,63 \%$, essa variação está relacionada diretamente com o estado das dunas e do cordão arenoso (MMA, 2010).

A vegetação carrasco, diferentemente da restinga, teve uma queda na sua área total de ocupação. No ano 2000, essa vegetação correspondia a 7,43\% do território total do município, em 2015 ela representa apenas a $5,58 \%$, segundo a dinâmica, essa variação está diretamente relacionada a questões que envolvem o solo exposto e a vegetação de caatinga, como pode ser observado no mapa, é uma área cercada por essas duas classes que, segundo a tabela da dinâmica, influenciaram diretamente ao longo dos anos.

Como observado, a análise ambiental a partir do estudo da dinâmica do uso e cobertura das terras entre 2000 e 2015, fornece subsídios a população e aos órgãos públicos sobre as alterações consideradas no ambiente, podendo ser apontado ainda como padrão de mudança a servir de base para o planejamento estrutural, econômico e ambiental beneficiando futuramente a população e o meio ambiente.

\section{CONCLUSÃO}

As classes de uso e cobertura das terras identificadas na região foram corpos d'água, área urbana, área úmida, cordão arenoso, solo exposto, vegetação de restinga, caatinga, carrasco e mangue, ocorrendo alterações seja de crescimento ou redução em termos de área no intervalo de tempo estudado.

A dinâmica temporal de uso e cobertura das terras mostrou que em média, a vegetação manteve certa estabilidade entre os anos de 2000 e 2015, mas mostrou também que a água teve um aumento significativo, indicando a expansão da aquicultura, outras classes também mantiveram uma certa preservação.

Foi possível perceber a importância do mapeamento de uso e cobertura das terras na busca por informações que auxiliam nas interpretações e análises sobre a evolução da paisagem na região, sendo dados que podem beneficiar o planejamento e ordenamento territorial do município.

\section{AGRADECIMENTOS}

A FAPEPI (Fundação de Amparo à Pesquisa do Piauí) pelo pagamento de bolsa à primeira 
autora. Ao CNPq (Conselho Nacional de Desenvolvimento Científico e Tecnológico) pelo financiamento do projeto proc. 443176/2014-0 e pela bolsa do segundo autor proc. 301254/2017-6. Aos laboratórios de Geomática e Solos e Sedimentos da UFPI (Universidade Federal do Piauí).

\section{REFERÊNCIAS}

ANDRADE-LIMA, D. Vegetação. In: LINS. R. C. Bacia do Parnaíba: aspectos fisiográficos. Recife: Instituto Joaquim Nabuco de Pesquisas Sociais, 1978. 9 v. (Série estudos e pesquisas).

ALBUQUERQUE, a. G. B. M., FREITAS, e. M. N., MOURA-FÉ, M. M., BARBOSA, W. R. A Proteção do Ecossistema Manguezal pela Legislação Ambiental Brasileira. GEOgraphia, v. 17(33), p. 126-153, 2015. https://doi.org/10.22409/GEOgraphia2015.17 33.a13700

BRASIL. (2012a). Lei Federal n ${ }^{\circ} 12.651$, de 25 de maio de 2012. Dispõe sobre o Código Florestal. Disponível em: <http://www.planalto.gov.br/ccivil_03/_ato20 11-2014/2012/lei/l12651.htm> Acesso: jul. 2020

BRASIL. (2012b). Lei Federal n ${ }^{\circ} 12.727$, de 17 de outubro de 2012. Dispõe sobre alterações no Código Florestal.

BAPTISTA, E. M. C. Estudo morfossedimentar dos recifes de arenito da zona litorânea do estado do Piauí, Brasil. Tese (Doutoramento em Geografia) Florianópolis: UFSC. 2010.

CÂMARA, G.; MEDEIROS, J. S. Geoprocessamento para projetos ambientais. São José dos Campos: INPE, 1996.

CAVALCANTI, A, P.B. Impactos e condições ambientais da zona costeira do Estado do Piauí. (Doutorado em Geografia) - Rio Claro: UNESP. 2000.
CPRM. Mapa Geológico do Estado do Piauí. Teresina: CPRM, 2006.

FONSECA, L. M. G. Processamento digital de imagens. São Paulo: INPE, 2000.

IBGE. Instituto brasileiro de Geografia e Estatística. Censo Demográfico 2010. Disponível em: $<$ http://www.ibge.gov.br/cidadesat/index.php >. Acesso em: 18 fev. 2018.

INMET. Instituto Nacional de Meteorologia. Disponível em: < https://portal.inmet.gov.br/>. Acesso em: 12 jul. 2020

JENSEN, J. R. Sensoriamento remoto do ambiente: uma perspectiva em recursos terrestres. Tradução da $2^{\text {a }}$ edição. São José dos Campos: Parêntese, 2009.

MMA. Ministério do Meio Ambiente. Áreas Prioritárias para Conservação, Uso Sustentável e Repartição de Benefícios da Biodiversidade Brasileira: Atualização - Portaria MMA n 9 , de 23 de janeiro de 2007. Brasília: MMA, 2007.

. Ministério do Meio Ambiente. Panorama da conservação dos ecossistemas costeiros e marinhos no Brasil. SBF/GBA, Brasília: MMA, 2010.

Avaliação e ações prioritárias para a conservação da biodiversidade da caatinga. Brasília: MMA, 2002.

PERROCA, M. G.; GAIDZINSKI, R. R. Avaliando a confiabilidade interavaliadores de um instrumento para classificação de pacientes - coeficiente Kappa. Rev. Esc. Enferm. USP, vol. 37, p. 72-80, 2003. https://doi.org/10.1590/S00806234200300010 0009

RADAMBRASIL. Série Levantamento de Recursos Naturais. Rio de Janeiro: FIBGE:, 1983. $32 \mathrm{v}$.

ROSA, R. Introdução ao sensoriamento remoto. $5^{\text {a }}$ ed. Uberlândia: EDUFU, 2003.

VENTURI, L. A. B. A dimensão territorial da paisagem geográfica. Congresso Brasileiro de Geógrafos, Goiânia, 2004, p. 11. 